\title{
In situ and satellite surface temperature records in Antarctica
}

\author{
Christopher A. Shuman, ${ }^{1,2}$ Josefino C. Comiso ${ }^{2}$ \\ ${ }^{1}$ Earth System Science Interdisciplinary Center, University of Maryland, College Park, MD 20742-2465, U.S.A. \\ ${ }^{2}$ Oceans and Ice Branch, Laboratory for Hydrospheric Processes, NASA Goddard Space Flight Center, Code 971, Greenbelt, MD 20771, U.S.A.
}

\begin{abstract}
Air-temperature records $\left(T_{\mathrm{A}}\right)$ during 1992 from five inland Antarctic automatic weather station (AWS) sites were compared with the best available infrared temperatures $\left(T_{\mathrm{IR}}\right)$ from the Advanced Very High Resolution Radiometer (AVHRR) as well as calibrated passive-microwave temperatures $\left(T_{\mathrm{C}}\right)$ from the Special Sensor Microwave/Imager $(\mathrm{SSM} / \mathrm{I})$. Daily and monthly average $T_{\mathrm{A}}, T_{\mathrm{IR}}$, and $T_{\mathrm{C}}$ data indicate that each approach captures generally similar trends at each site but each approach also has limitations. AWS $T_{\mathrm{A}}$ data are considered the most accurate but represent spatially restricted areas and may have long gaps due to sensor or transmission problems. AVHRR $T_{\mathrm{IR}}$ data have daily variability similar to the $T_{\mathrm{A}}$ record but have numerous small gaps due to cloud cover or observation interruptions. An offset between $T_{\mathrm{A}}$ and $T_{\mathrm{IR}}(>4 \mathrm{~K})$ at the South Pole site was identified that may be due to the inclusion of data with large satellite scan angles necessary to cover this area. SSM/I $T_{\mathrm{C}}$ data have the most continuity but exhibit calibration problems, a significantly damped daily response and do not cover all of Antarctica. Individual daily differences between $T_{\mathrm{A}}$ and $T_{\mathrm{IR}}$ as well as $T_{\mathrm{A}}$ and $T_{\mathrm{C}}$ can exceed $17 \mathrm{~K}$, but all sites have mean daily differences of about $1 \mathrm{~K}$ or better, after compensating for the offset at South Pole, and standard deviations of $<6 \mathrm{~K}$. Monthly temperature differences are typically $5 \mathrm{~K}$ or better, with standard deviations generally $<3 \mathrm{~K}$. And finally, using the available data, the 1992 average temperature differences are $<1 \mathrm{~K}$.
\end{abstract}

\section{INTRODUGTION}

Detection of climate change involves determining a multiyear baseline for a climate parameter and then detecting variations that exceed its observed range over the baseline period. Increasing temperatures, possibly linked to global climate warming, have been detected at sites on the Antarctic Peninsula (Jacka and Budd, 1991; King, 1994; Vaughan and Doake, 1996). Further inland, at specific automatic weather stations (AWSs), data on near-surface temperature $\left(T_{\mathrm{A}}\right)$ are beginning to define a climate baseline (Shuman and Stearns, 2001). However, these data have significant gaps and may not be representative of broader regional or continental-scale patterns. Temperature fields derived from satellite infrared (Comiso, 2000) or passive-microwave sensors can provide a much more complete characterization of spatial and temporal variations in Antarctic temperature. Currently, the only spatially detailed record of surface temperature across Antarctica is provided by Advanced Very High Resolution Radiometer (AVHRR) infrared channels $\left(T_{\mathrm{IR}}\right)$, but they must be carefully processed to remove the effects of clouds (Comiso, 2000). Passive-microwave data from the $37 \mathrm{GHz}$ channel of the Special Sensor Microwave/Imager $(\mathrm{SSM} / \mathrm{I})$ are not influenced by cloud cover and can be calibrated $\left(T_{\mathrm{C}}\right)$ at specific AWS locations (Shuman and others, 1995) or by complex radiative transfer models (Fung and Chen, 1981; Comiso and others, 1982), but cannot yet be broadly extrapolated in space and time because of still poorly understood spatial variations in the emissivity of the surface. Time series of these satellite data, if they could be used consistently, would provide the temperature data needed to identify regional and continentalscale climate change across Antarctica. This study, using recently published temperature data, analyzes in situ and satellite temperature information, and documents the advantages and limitations of each approach. The intent of this study is to use the AWS data to gain insight into the accuracy of the surface temperatures retrieved from satellite infrared and microwave sources and establish confidence limits on these data.

Table 1. Site data for inland Antarctic AWS temperature records

\begin{tabular}{lcrrccc}
\hline AWS name & Location & Elevation & Grid & Start & Stop \\
& & $\mathrm{m}$ & & & \\
& & & & & \\
\hline Byrd & $80.01^{\circ} \mathrm{S}, 119.40^{\circ} \mathrm{W}$ & 1530 & 121196 & Feb. 1980 & \\
Clean Air & $90.00^{\circ} \mathrm{S}, 120.00^{\circ} \mathrm{W}$ & 2835 & & Jan. 1986 & \\
Lettau & $82.52^{\circ} \mathrm{S}, 174.45^{\circ} \mathrm{W}$ & 55 & 155206 & Jan. 1986 & \\
Lynn & $74.21^{\circ} \mathrm{S}, 160.41^{\circ} \mathrm{E}$ & 1772 & 182239 & Jan. 1988 & Jan. 1998 \\
Siple & $75.90^{\circ} \mathrm{S}, 84.00^{\circ} \mathrm{W}$ & 1054 & 97168 & Jan. 1982 & Apr. 1992 \\
& & & & & & \\
\hline
\end{tabular}

Notes: This analysis is based on available 3 hourly average data taken from the University of Wisconsin server in March 1999. The grid column contains the coordinates of the $25 \mathrm{~km}$ SSM/I pixel covering the AWS location. There is no SSM/I coverage at the South Pole, where AWS Clean Air is located. 


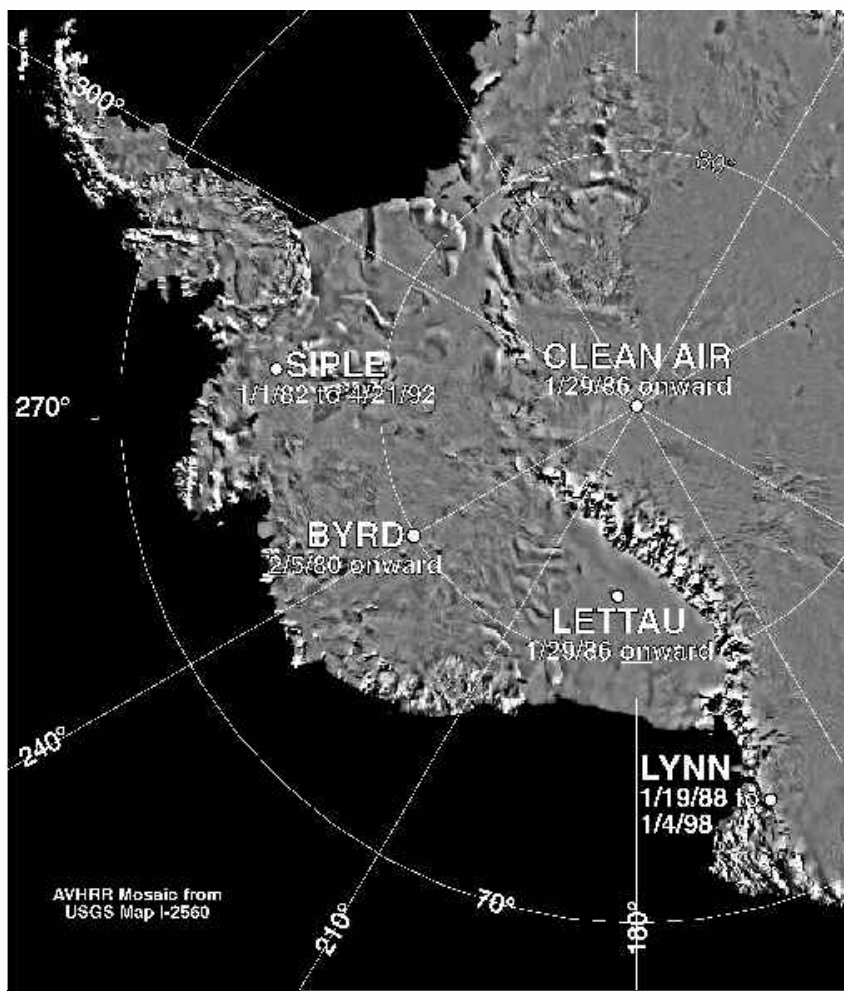

Fig. 1. The locations and dates of operation of the five inland Antarctic AWSs used in this study. Dates are $\mathrm{mm} / \mathrm{dd} / \mathrm{yy}$.

This project used three types of temperature data from 1992 that were spatially and temporally co-registered:

(1) daily-average $T_{\mathrm{A}}$ records from five AWSs in Antarctica operated by the University of Wisconsin (see Fig. 1; Table 1);

(2) daily-average AVHRR $T_{\mathrm{IR}}$ data compiled and processed as described in Comiso (2000); and

(3) daily-average $T_{\mathrm{C}}$ data derived from the SSM/I datasets compiled by the U.S. National Snow and Ice Data Center (NSIDG) and calibrated as described in Shuman and Stearns (2001).

The three measurements are not exactly for the same physical parameter since the AWS measures near-surface air temperature $(\sim 2 \mathrm{~m})$, the infrared sensor measures skindepth temperature, and the passive-microwave sensor measures the average temperature of the upper surface layer. This comparative analysis will help establish how the three datasets can be used in conjunction to study the variations of an important climate parameter through time.

\section{STATEMENT OF PROBLEM}

Near-surface air-temperature data have been consistently monitored by AWS since 1980 at some sites, and many of these observations continue to the current day (Shuman and Stearns, 2001). However, as the data in Figure 2 illustrate, the records from Antarctic AWS sites are not continuous. Because of equipment and logistics challenges in this harsh environment, AWS records may be composed of segments that are separated by temporal gaps of considerable length. These data gaps complicate the effort of long-term in situ climate monitoring. In addition, AWS $T_{\mathrm{A}}$ data may not perfectly represent actual temperature at all times. For example, minor increases due to solar heating have been suggested at some ice-sheet locations (Shuman and others, 2001). See Comiso (2000) for a detailed analysis of in situ temperature records from Antarctic sites.

AVHRR data have been available since the 1970s, but it was not until 1981 that digital versions of continuous orbital records became available. Their wide swath $(2240 \mathrm{~km})$ and a revisit time of about 102 min makes AVHRR data suitable for variability studies of surface temperatures at a reasonably good temporal resolution. For temperature studies, a large fraction of the data, however, must be discarded because of cloud effects since infrared radiation cannot penetrate through the clouds. Nevertheless, because of a relatively high sampling rate, there are enough cloud-free surface data to cover the entire Antarctic region in a week. Weekly maps of the entire Antarctic region can thus be produced with AVHRR, but because of residuals in the cloud masking, these are not as accurate as the monthly maps where the averaging of more observations makes the impact of any cloud-contaminated pixels less prominent.

Passive-microwave brightness temperatures $\left(T_{\mathrm{B}}\right)$ from Antarctica also begin in the 1970s, from 1978 onward consistently, and can be an effective surrogate temperature indicator over polar snow if they can be accurately calibrated into $T_{\mathrm{C}}$ values (see Fig. 2). The $T_{\mathrm{B}}$ data do not provide a pure temperature signal, however; they are a function of the characteristics of the snow and ice over the depth of emission (Shuman and others, 1995; Shuman and Stearns, 2001). This means that passive-microwave data cannot be used directly to substitute for missing $T_{\mathrm{A}}$ or $T_{\mathrm{IR}}$ temperatures but must first be calibrated to account for approximately annual variations in snow-emission characteristics. As discussed in Shuman and others (1995), radiative transfer modeling will account for all the factors that influence the conversion of $T_{\mathrm{B}}$ data into temperature estimates. Currently, however, field observations are required to account for variations in snow characteristics, so this approach is not yet widely applicable. A temperature inferred from the passive-microwave data represents the average of a layer of snow that may vary in thickness from one location to another because of changes in snow properties. Depending on frequency, the penetration depth can be as much as a few meters, but is thought to be a few tens of centimeters for the $37 \mathrm{GHz}$ channel used here (Shuman and others, 1995). An additional complication for the passive-microwave technique is introduced by brief melt events in the vicinity of some Antarctic AWSs (Zwally and Fiegles, 1994; Abdalati and Steffen, 1997). Large brightness-temperature increases associated with the presence of liquid water do not significantly impact this analysis, but they are discussed later (see Fig. 3 and associated dates in the AWS Lettau $T_{\mathrm{C}}$ record (Fig. 2c)).

\section{METHODOLOGY}

The AWS data were obtained from the 3 hourly files at the anonymous file transfer protocol (ftp) site operated by the University of Wisconsin, Madison. These data are qualitycontrolled samples of $10 \mathrm{~min}$ AWS observations that are also available from this site (ftp://ice.ssec.wisc.edu/). The dailyaverage $T_{\mathrm{A}}$ values are then derived from the 3 hourly data. Detailed information on the AWS units that are used here, including data transmission and quality control, is presented in Stearns and Weidner (1993) and Stearns and 
BYRD TEMPERATURE COMPARISON

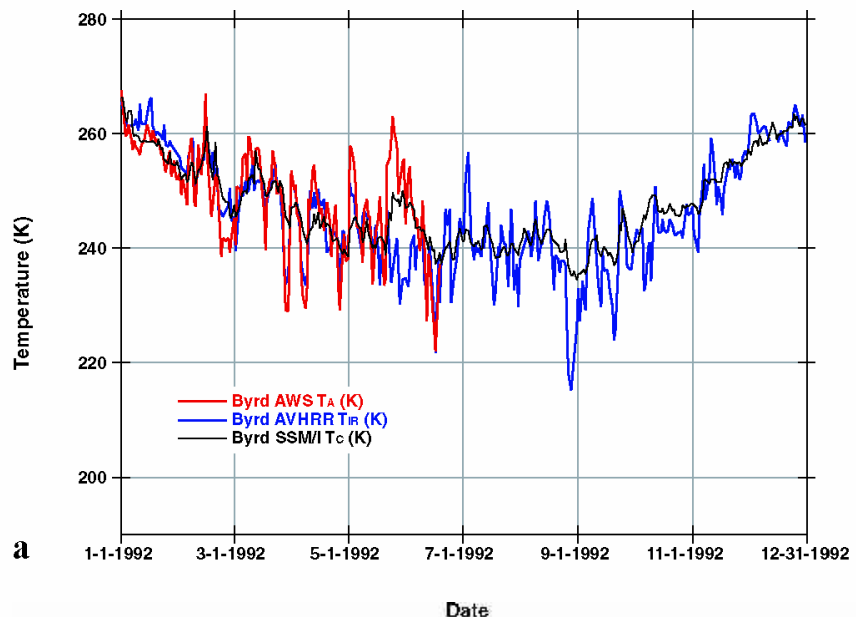

LETTAU TEMPERATURE COMPARISON

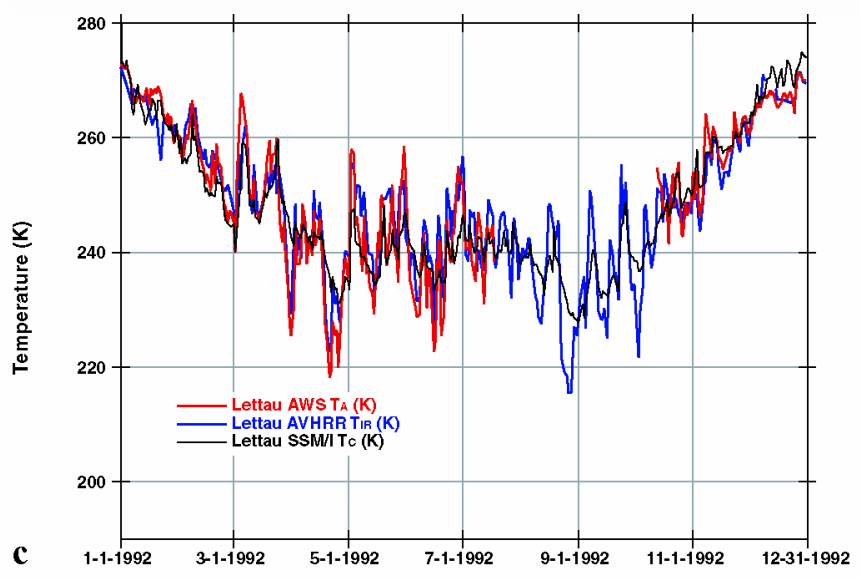

Date

SIPLE TEMPERATURE COMPARISON

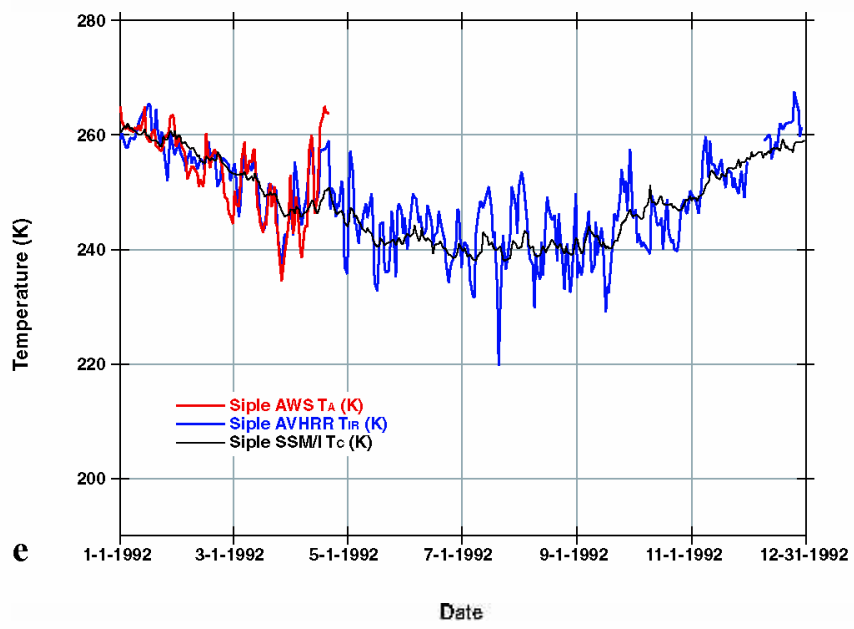

others (1993). These papers specify the temperature resolution of the AWS sensors as $0.125^{\circ} \mathrm{C}$. Absolute calibration in the longer term and adjustments to sensor height as snow accumulates remain problems for $T_{\mathrm{A}}$ data (Shuman and Stearns, 2001; Shuman and others, 2001).

The technique for using infrared data to obtain skindepth temperature maps of the polar regions has been discussed previously (Steffen and others, 1993; Stroeve and Steffen, 1998; Comiso, 2000). The key infrared sensor has been the AVHRR because of continuous and long-term coverage. The sensor has five channels, from the visible to thermal infrared, but it is the thermal channel at $11 \mu \mathrm{m}$ that is used to estimate surface
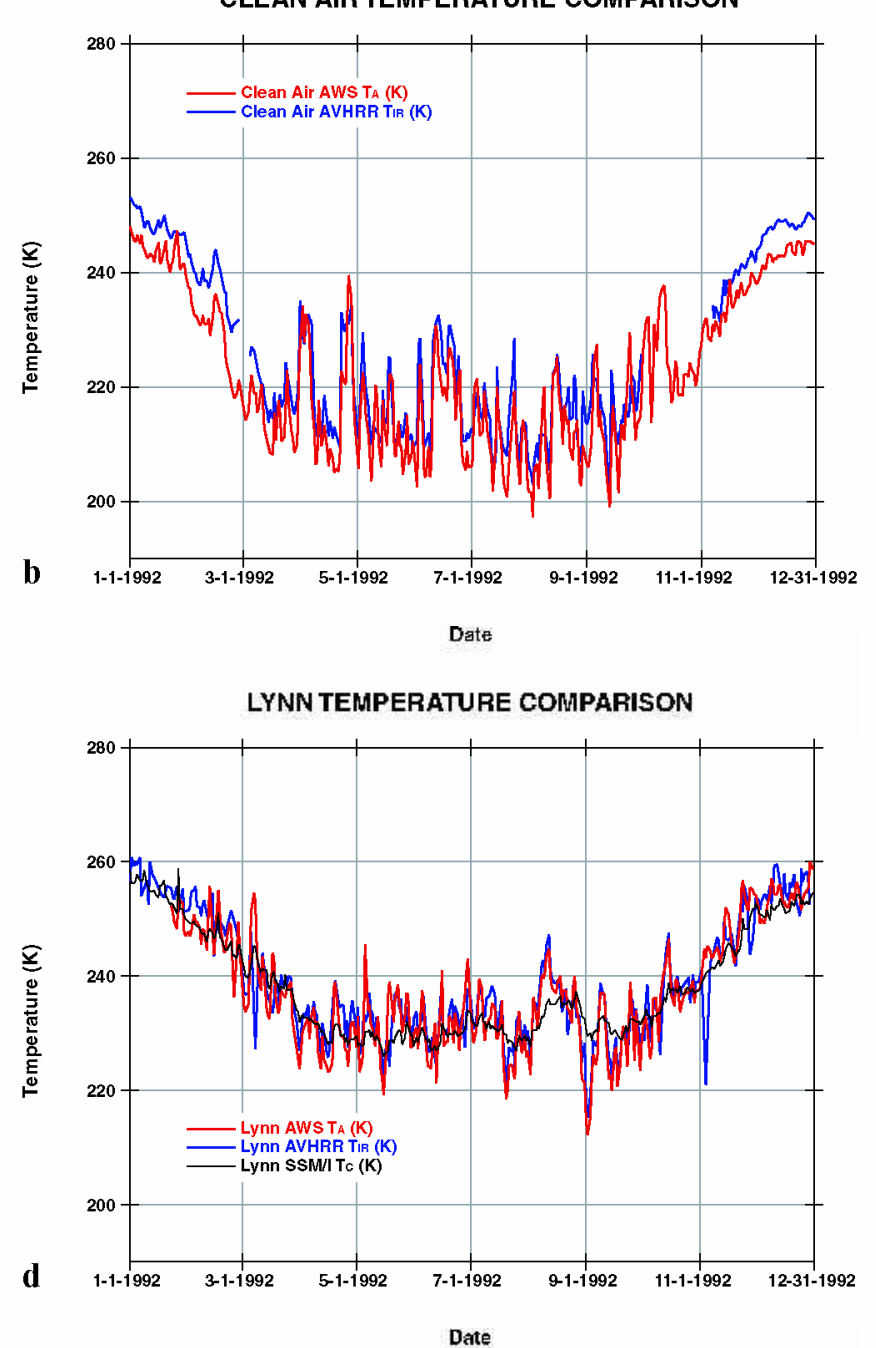

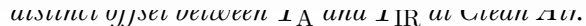

temperatures, while the other channels are used for cloud masking and atmospheric correction. Also, clouds are especially difficult to discriminate from snow surfaces in the data, and although a special masking technique has been used (Comiso, 2000) in addition to conventional techniques, some cloud-impacted pixels remain. It is their presence that is thought to cause some of the larger errors in this daily dataset. However, because this problem occurs in different places at different times, the impact on the accuracy of the monthly data, which is a standard climatology product (Genthon and Braun, 1995), is not as great because of the averaging period. The AVHRR dataset used for this study is the Global Area 


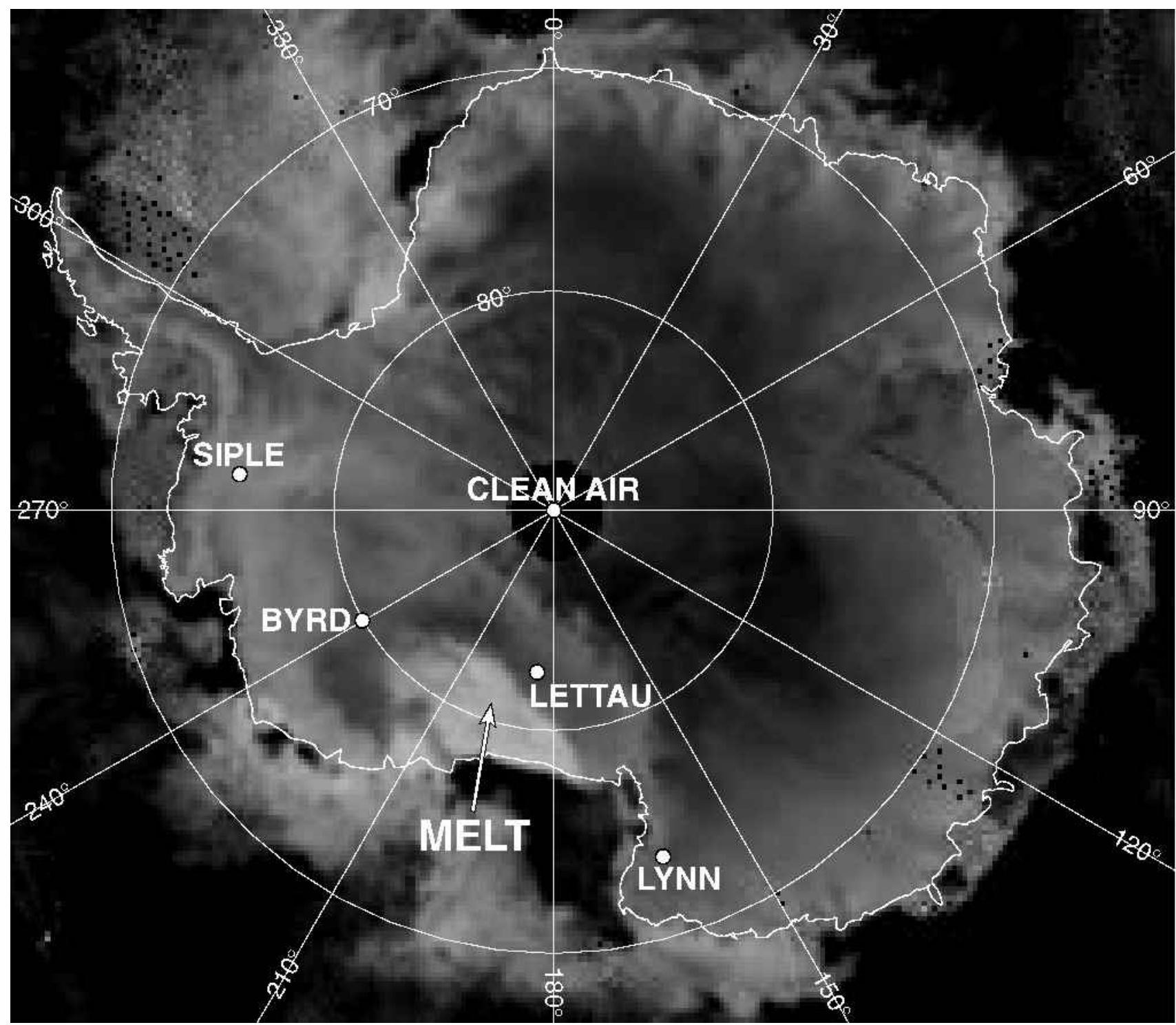

Fig. 3. Illustration of the spatial extent of a melt event (lighter gray tones) that briefly impacts the Lettau $T_{\mathrm{C}}$ record. The event lasted from approximately 21 December 1991 to 6 June 1992 and reached its apparent maximum extent on 23 December 1991 (illustrated). This daily average SSM/I 37 GHz horizontal polarization image also shows the coverage gap around South Pole, and inconsistent data values associated with an isolated sensor sweep in East Antarctica.

Coverage (GAC) dataset that has a resolution of $5 \mathrm{~km}$ by $3 \mathrm{~km}$ at nadir. The continuous orbital dataset was acquired from the NASA Goddard Space Flight Center AVHRR Pathfinder Project that did much of the original quality control. The data were subsequently mapped to polar stereographic maps similar to that used for passive microwave but at a resolution of $6.25 \mathrm{~km}$.

The passive-microwave data used here were extracted from NSIDG GD-ROMs (NSIDG, 1992). Daily-averaged, $37 \mathrm{GHz}$, vertical-polarization $(\mathrm{V})$ brightness temperatures $\left(T_{\mathrm{B}}\right)$ from the SSM/I-F11 for the $25 \times 25 \mathrm{~km}$ gridcell covering each AWS site were compiled to document their multiyear "temperature" trends for each site. The South Pole record examined here cannot be studied by this technique, as it is not covered by passive-microwave data (see Fig. 3). Brightness-temperature data from the $37 \mathrm{GHz} \mathrm{V}(0.81 \mathrm{~cm}$ wavelength) channel begin in 1978 and continue through the present day. The $T_{\mathrm{B}}$ measurement accuracy of the $37 \mathrm{GHz} \mathrm{V}$ channels on this instrument is $\pm 2 \mathrm{~K}$ for the SSM/I (Hollinger and others, 1990). The $37 \mathrm{GHz} V T_{\mathrm{B}}$ data are calibrated using AWS air temperatures by an emissivity modeling technique (Shuman and others, 1995; Shuman and Stearns, 2001) to create the $T_{\mathrm{C}}$ time series to be compared to the $T_{\mathrm{A}}$ and $T_{\mathrm{IR}}$ data.

\section{RESULTS AND DISGUSSION}

The daily temperature plots (Fig. 2) illustrate the challenge of interpreting temperature data from different datasets in Antarctica for just 1 year. Although each of the temperature records documents the same general annual trend, there are characteristics that need to be understood with each dataset. The Byrd record is $<50 \%$ complete for $T_{\mathrm{A}}$ and contains a several-week period (late May to early June) where $T_{\mathrm{IR}}$ appears to be too low. The Clean Air site has a distinct offset between $T_{\mathrm{A}}$ and $T_{\mathrm{IR}}$ throughout the year, as well as gaps in $T_{\mathrm{IR}}$. The Lettau record has a roughly 3 month gap in $T_{\mathrm{A}}$, and the Siple record has less than one-third of a year of $T_{\mathrm{A}}$ data (this AWS ceased operations in 1992). Only the Lynn record is substantially complete for 1992, but this AWS too is no longer operating (see Fig. 1; Table 1). For each site, the 


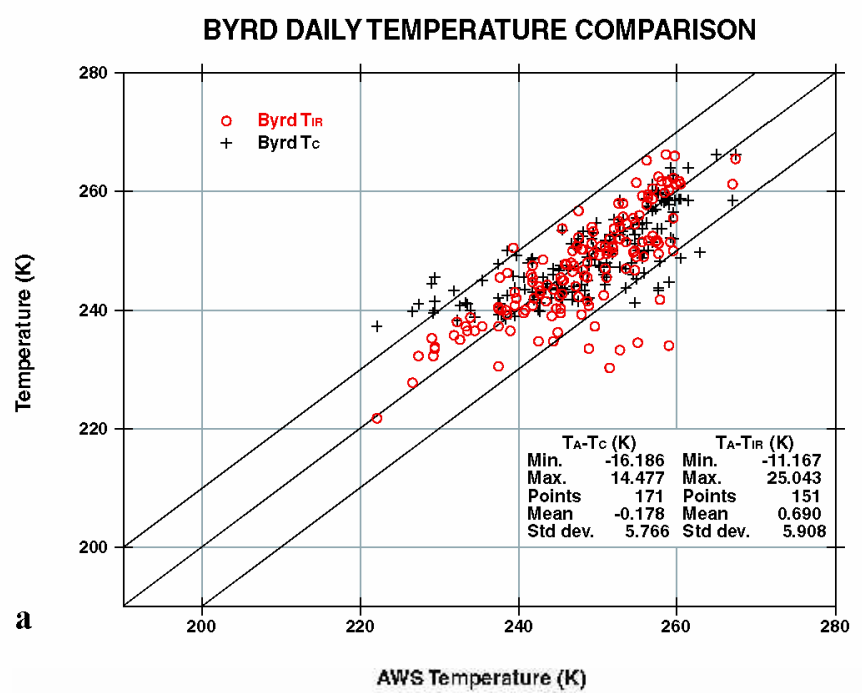

LETTAU DAILY TEMPERATURE

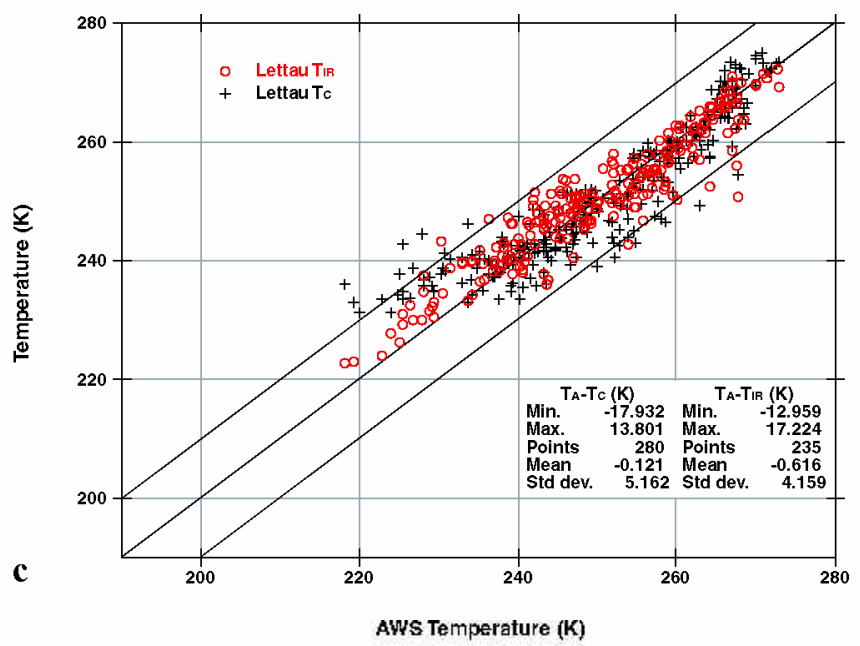

SIPLE DAILY TEMPERATURE COMPARISON

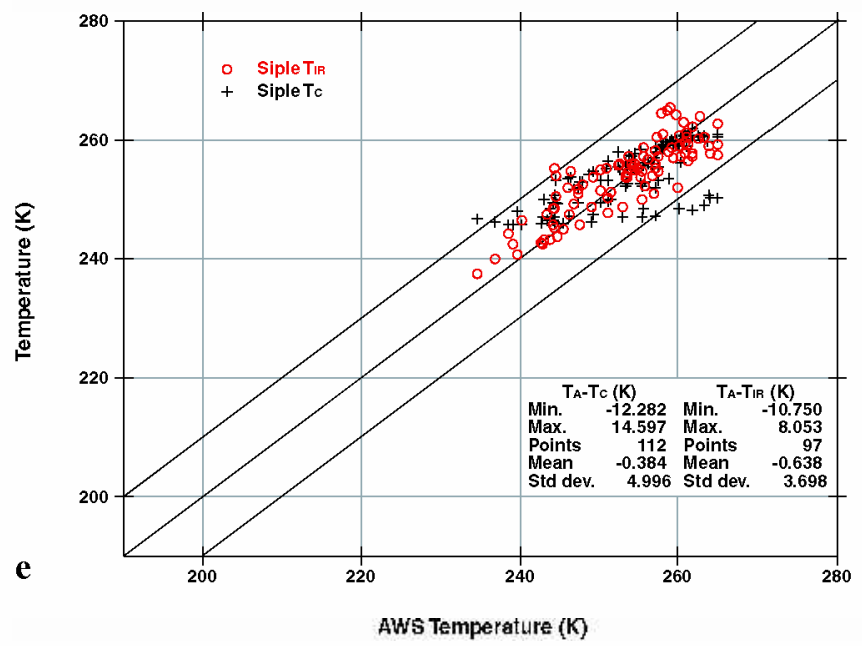

$T_{\mathrm{C}}$ data are complete (see Shuman and Stearns, 2001) but are considerably less variable due to their dependence on emission from the near-surface snow. Incidentally, this analysis is arbitrarily focused on 1992 largely because of the availability of daily $T_{\mathrm{IR}}$ data for that particular year (see Comiso, 2000, for details). Unfortunately, this focus on 1992 will limit to some extent the comparisons capable of being conducted from these data. Further work on additional years of data is planned to insure that the conclusions based on 1992 are representative.
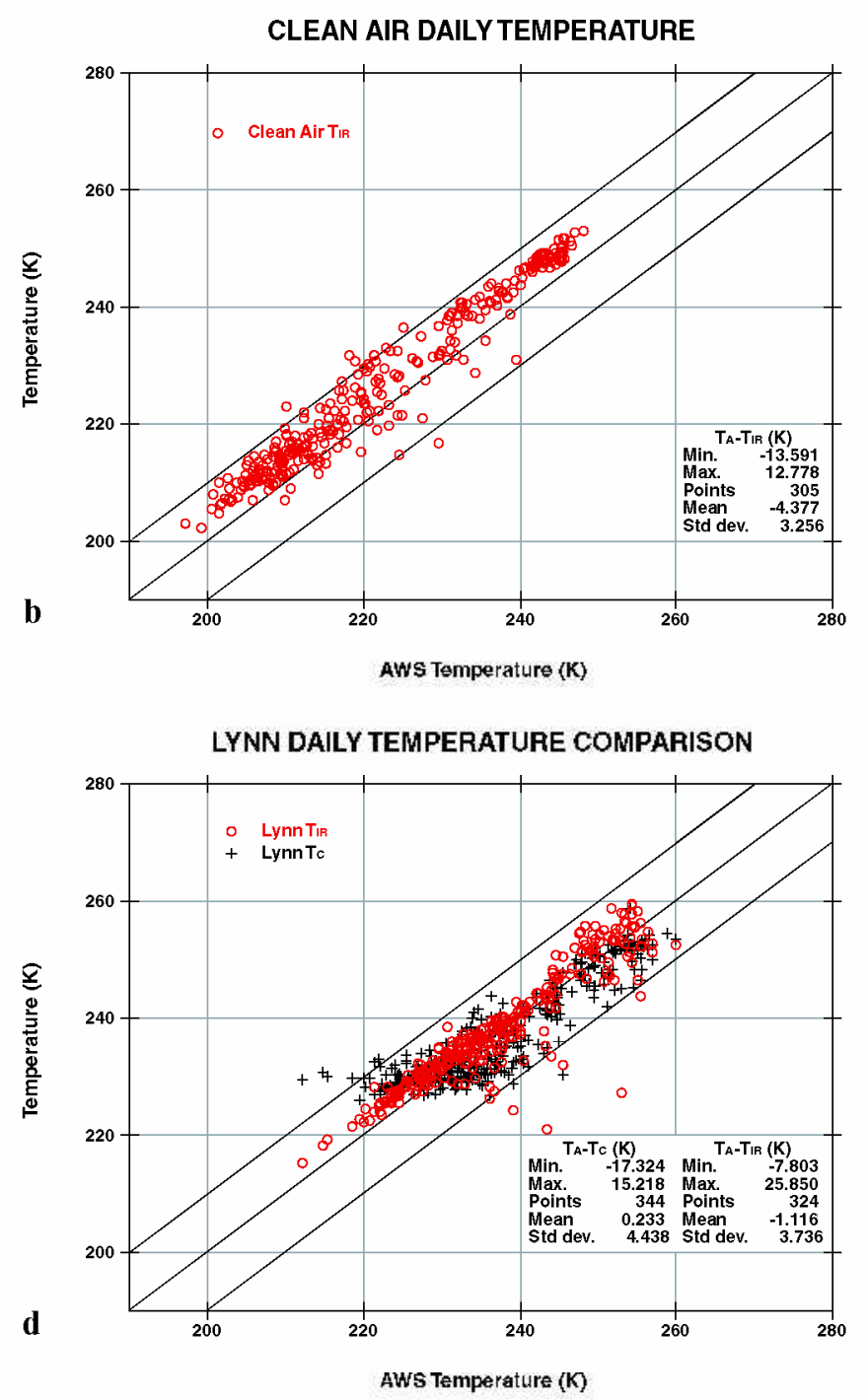

strongly negative).

The plots in Figure 4 illustrate the overall relationship between the two satellite temperature records and the in situ measurements. Daily differences can be estimated visually from the plots in Figure 2. The satellite measurements necessarily cover a larger region (four $\sim 6 \times 6 \mathrm{~km}$ pixels for $T_{\mathrm{IR}}$ and a $25 \times 25 \mathrm{~km}$ pixel for $T_{\mathrm{C}}$ ) than that measured by the "point source" AWS. Therefore, exact correspondence between the datasets is unlikely. In general, the Figure 4 plots show that the $T_{\mathrm{IR}}$ data have a strong correlation with $T_{\mathrm{A}}$, as the majority of daily values fall in the $\pm 10 \mathrm{~K}$ range along the zero-difference 
Table 2. Difference statistics for all 1992 daily mean temperatures

\begin{tabular}{lccccc}
\hline & Byrd & Clean Air & Lettau & Lynn & Siple \\
\hline$T_{\mathrm{A}}-T_{\mathrm{IR}}$ & & & & & \\
$\quad$ Difference & 0.69 & -4.38 & -0.62 & -1.12 & -0.64 \\
$\quad$ Days & 151 & 305 & 235 & 324 & 97 \\
& & & & & \\
$T_{\mathrm{A}}-T_{\mathrm{C}}$ & & & -0.12 & 0.23 & -0.38 \\
$\quad$ Difference & -0.18 & & 280 & 344 & 112 \\
$\quad$ Days & 171 & & & & \\
\hline
\end{tabular}

Notes: This analysis is based on all days where there was both an air temperature $\left(T_{\mathrm{A}}\right)$ and an AVHRR infrared temperature $\left(T_{\mathrm{IR}}\right)$ or a calibrated SSM/I temperature $\left(T_{\mathrm{C}}\right)$. There are no $T_{\mathrm{C}}$ data for AWS Clean Air due to the hole in SSM/I coverage at the South Pole.

line. The same is true of the $T_{\mathrm{C}}$ data, but they tend to overestimate temperature at the low end of the data range. All averages discussed here are based on exactly corresponding dates. This means the datasets are as compatible as possible. Table 2 summarizes the daily-temperature difference data.

With the exception of the period in late May and early June at Byrd where $T_{\mathrm{IR}}$ values are too low (Fig. 4a), infrared temperature estimates track $T_{\mathrm{A}}$ closely at all the sites except Clean Air. The $T_{\mathrm{IR}}$ values there show a consistent offset, with a mean difference value of $>4 \mathrm{~K}$ (Fig. $4 \mathrm{~b}$ ). The offset is distinctly linear across the temperature range, suggesting that it should be possible to compensate for it in the AVHRR processing algorithm. Preliminary examination of the problem suggests it may be the result of the scan angle needed to retrieve data at this latitude. In general, data from scan angles closer to nadir $\left( \pm 48.5^{\circ}\right.$ instead of the $55.4^{\circ}$ needed to cover the South Pole) are used for temperature retrievals (Comiso, 2000). It should be noted that assigning the offset entirely to the infrared data assumes that the AWS data are always accurate, even though some problems with $T_{\mathrm{A}}$ are known to occur (Shuman and others, 2001). Similarly, the Lynn data (Fig. 4d) also show a small offset from $T_{\mathrm{A}}$ that suggests $T_{\mathrm{IR}}$ values here are apparently more than $1 \mathrm{~K}$ too high. Overall, scatter in these data is likely a result of incomplete cloud masking, and its daily magnitude is suggested by the standard deviation values shown in Fig. 4. Averaging the daily data to derive monthly values diminishes the impact of any individual day's data (Comiso, 2000).

The $T_{\mathrm{IR}}$ values are thought to be too low during late May and early June at Byrd largely because the $T_{\mathrm{C}}$ values show a temperature trend similar to but smaller than that of $T_{\mathrm{A}}$ values during this period. As noted above, the tendency for $T_{\mathrm{C}}$ data to overestimate temperature is illustrated by values plotting above even the upper diagonal lines at Byrd, Lettau and Lynn (the $T_{\mathrm{A}}-T_{\mathrm{C}}$ difference is negative). The scatter plots shown in Figure 4 also suggest a slight curvature (see Fig. 4c) that can be traced to the technique's tendency to slightly overestimate emissivity in the spring and fall and slightly underestimate it in the winter and summer (Shuman and others, 1995). The winter period seems to be the most significant at these sites, for reasons which are not well understood but are probably related to the emissivity correction not being the simple sinusoid that is currently required by the technique.

The monthly difference plots (see Fig. 5) show smaller means and standard deviations as discussed above. These plots give confidence that these temperature data can be used in cli-
Table 3. Difference statistics for all 1992 monthly mean temperatures

\begin{tabular}{lccccc}
\hline & Byrd & Clean Air & Lettau & Lynn & Siple \\
\hline $\begin{array}{l}T_{\mathrm{A}}-T_{\mathrm{IR}} \\
\text { Difference }\end{array}$ & 0.64 & -4.29 & -0.57 & -1.23 & -0.59 \\
$\quad$ Months & 6 & 12 & 10 & 12 & 4 \\
$T_{\mathrm{A}}-T_{\mathrm{C}}$ & & & & & \\
Difference & -0.38 & & -0.12 & 0.12 & -0.05 \\
Months & 6 & & 10 & 12 & 4 \\
\hline
\end{tabular}

Notes: This analysis is based on all days of a calendar month where there was both an air temperature $\left(T_{\mathrm{A}}\right)$ and an AVHRR infrared temperature $\left(T_{\mathrm{IR}}\right)$ or a calibrated SSM/I temperature $\left(T_{\mathrm{C}}\right)$. There are no $T_{\mathrm{C}}$ data for AWS Clean Air due to the hole in SSM/I coverage at the South Pole.

matological analyses (Genthon and Braun, 1995). All differences are within $5 \mathrm{~K}$ of the zero line if the problematic period at Byrd is discounted and the offset is corrected at Clean Air in the $T_{\mathrm{IR}}$ data. The mean values for both $T_{\mathrm{A}}-T_{\mathrm{IR}}$ and $T_{\mathrm{A}}-T_{\mathrm{C}}$ are $<1 \mathrm{~K}$ at all sites if allowance is made for the small $T_{\mathrm{IR}}$ offset previously noted at Lynn. The reasons for the offset at Lynn are unclear but may be connected with the relatively steeper topography (in the immediate vicinity of the AWS; see Fig. 1). In other words, the satellite view of the site may cover more variable topography than at the less mountainous AWS sites, and the $T_{\mathrm{IR}}$ values may not as accurately match $T_{\mathrm{A}}$ as a result. Table 3 summarizes the monthly-temperature-difference data.

Because of the relatively short $T_{\mathrm{A}}$ records available for analysis at several of the AWS sites, annual mean comparisons with $T_{\mathrm{IR}}$ and $T_{\mathrm{C}}$ were not satisfactory representations of the true "annual" temperature. Consequently, annual means were calculated and differenced using the more complete $T_{\mathrm{IR}}$ and $T_{\mathrm{C}}$ values. This provides a more representative value and allows the uncertainty of these independent datasets to be conveniently evaluated (see Table 4). In all cases, the annual difference was $<1.5 \mathrm{~K}$. Note that the larger difference values at Byrd and Lynn include a period of problematic data and a distinct offset, respectively. These annual difference values provide a confidence limit on annual average data derived from satellite sources that is compatible with those reported in Shuman and Stearns (2001, fig. 10).

Comparative analysis has revealed unique characteristics and unexpected weaknesses of the satellite datasets. The daily infrared data show basically the same variability as the AWS data, but there are times when the differences are large. An examination of the values from individual AVHRR orbits that went into these daily data indicate that there are times when some values are a few standard deviations away from the daily average. This is likely due to imperfections in the cloud-masking technique, but further studies are required, especially through comparative analysis with the TERRA/MODIS (Moderate Resolution Imaging Spectroradiometer) data that may have the right set of channels for accurate cloud masking in the polar regions. The monthly averages, which are the final temperature product as reported by Comiso (2000), show better agreement with corresponding coastal AWS data and may be further improved through the use of an appropriate filtering technique. The daily microwave data show basically the same long-term variability as the other datasets, but do not capture short-term variability as well as the infrared or AWS data. This is likely associated with the microwave data 
BYRD MONTHLY TEMPERATURE

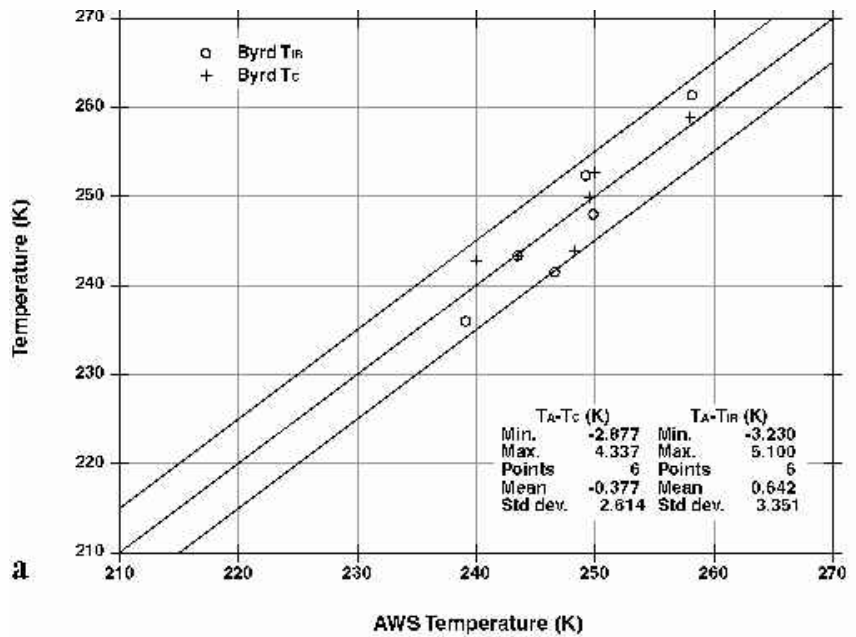

LETTAU MONTHLY TEMPERATURE

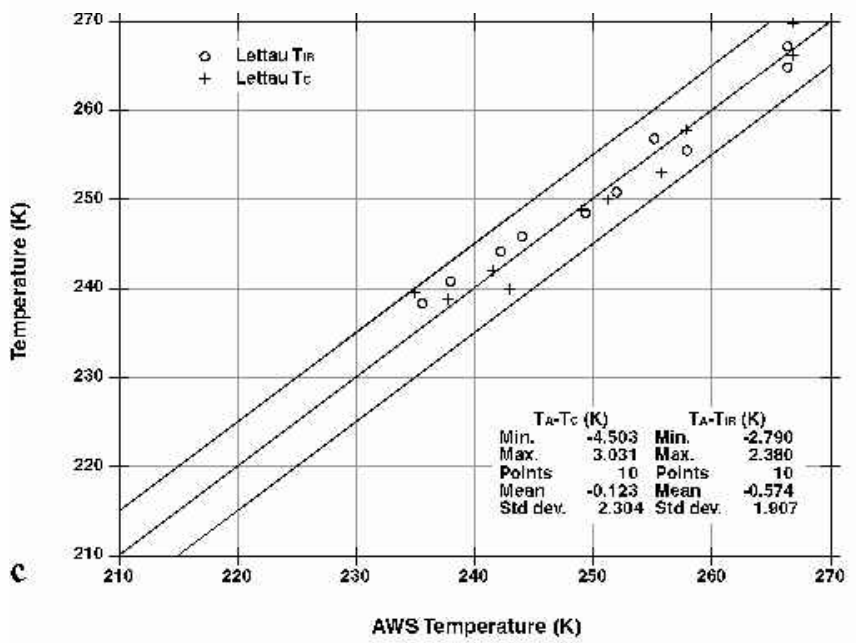

SIPLE MONTHLYTEMPERATURE

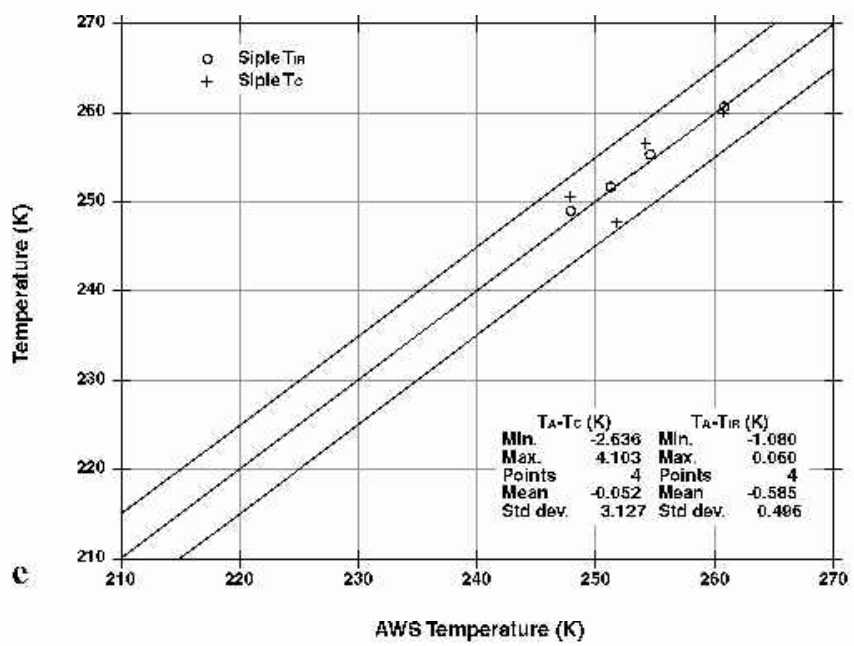

representing an average temperature that is less responsive to short-term fluctuations in atmospheric temperature. Because the snow surface is optically thin at microwave frequencies, the observed temperatures actually represent the average temperature of a layer of snow. And since snow is a good insulator, the short-term fluctuation of this layer may not be identical to that of the surface. However, temporal averages, starting with weekly averages of passive-microwave data, agree very well with both AWS data and infra-

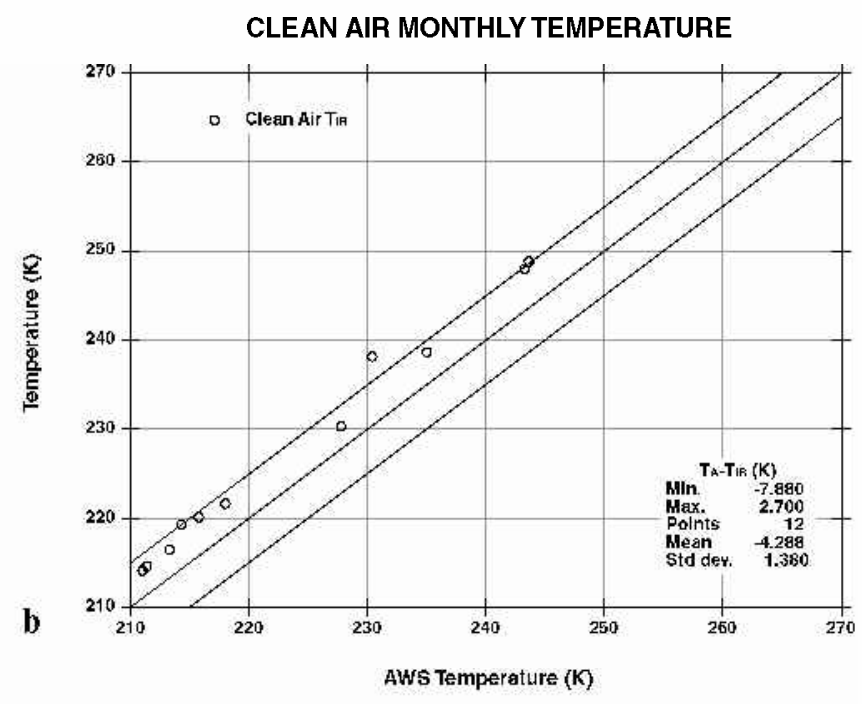

LYNN MONTHLY TEMPERATURE

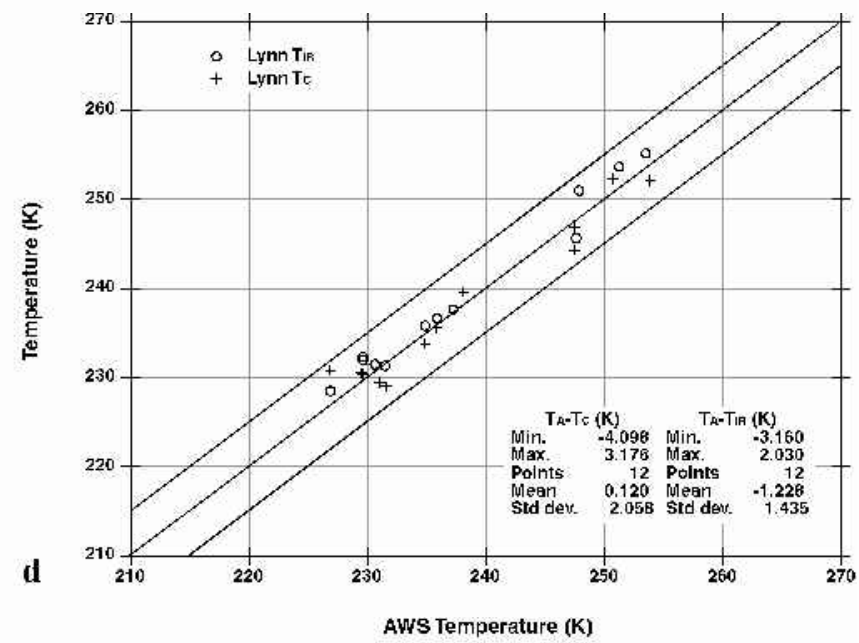

the center line represents $0 K$ difference.

red data. This makes the passive microwave a very useful dataset for filling in gaps in both infrared and AWS datasets.

\section{GONGLUSIONS}

The significance of this study is that it enabled an improved understanding of three currently available Antarctic surface temperature datasets. At present, the thermal infrared data 
Table 4. Difference statistics for all $1992 T_{\mathrm{IR}}$ and $T_{\mathrm{C}}$ daily mean temperatures

\begin{tabular}{lccccc}
\hline & Byrd & Clean Air & Lettau & Lynn & Siple \\
\hline Days & 323 & 305 & 313 & 342 & 328 \\
$T_{\mathrm{TR}}$ & 245.66 & 226.38 & 246.97 & 238.85 & 248.12 \\
$T_{\mathrm{C}}$ & 247.02 & & 246.64 & 237.64 & 247.61 \\
$T_{\mathrm{IR}}-T_{\mathrm{C}}$ & -1.36 & & 0.33 & 1.21 & 0.52 \\
& & & & & \\
\hline
\end{tabular}

Notes: This analysis is based on all days where there was both an AVHRR infrared temperature $\left(T_{\mathrm{IR}}\right)$ and a calibrated $\mathrm{SSM} / \mathrm{I}$ temperature $\left(T_{\mathrm{C}}\right)$. There are no $T_{\mathrm{C}}$ data for AWS Clean Air due to the hole in SSM/I coverage at the South Pole.

provide the only spatially detailed temperature distributions in Antarctica, but contain data gaps due to intermittent cloud cover. The passive-microwave data have the potential to provide spatially detailed, continuous and gap-free temperature distributions. However, more research is needed to correctly calibrate these data for regional changes in the radiative characteristics of the snow cover. The AWS data are the most accurate, but are the most difficult to use for large-scale scientific research because of their limited spatial coverage and gaps in the temporal series due to occasional instrument malfunction. The AWS data, however, provide the means to determine the value and the significance of both the infrared and the passive-microwave datasets.

These different near-surface temperature datasets are quite complementary and should enable the development of improved temperature baselines for sites in Antarctica. Although $T_{\mathrm{A}}$ data may be discontinuous, $T_{\mathrm{IR}}$ data can accurately fill most gaps at specific sites. Any gaps due to cloud cover in the $T_{\mathrm{IR}}$ record can then be filled with extrapolated $T_{\mathrm{C}}$ values, and these values also provide a reliability check on the spatially more extensive $T_{\mathrm{IR}}$ data. Processing requirements are significant, especially for $T_{\mathrm{IR}}$, however, and detecting and removing cloud impacts and accurately calibrating these data remains a challenge. Overall, this study has demonstrated that the satellite data compare quite well in most cases, assuming that these AWS $T_{\mathrm{A}}$ data reliably represent these locations. The limited comparisons presented here certainly justify continued efforts with additional years of data at these and other sites across the Antarctic continent. Although individual day differences between in situ and satellite temperatures can be quite large, the average errors are relatively small and appear well constrained. For the thermal infrared dataset, the standard products are the monthly averages that appear to provide a realistic representation of temperature distributions around the continent. Some of the discrepancies between the methods studied here are probably due to the differing spatial and temporal resolutions of the three different methods. We also have assumed that the AWS hardware for measuring temperature is always in perfect condition, which is not guaranteed in such an adverse environment, and there may be some instances when the AWS actually provides erroneous results despite quality-control procedures. For optimal accuracy, especially at high temporal resolution, a combination of the three methods may be necessary to determine an accurate climate baseline and then evaluate potential changes that may come in the years ahead.

\section{ACKNOWLEDGEMENTS}

We would like to thank the staff of the Antarctic Automatic Weather Stations Project (http://uwamrc.ssec.wisc.edu/aws/) at the University of Wisconsin and L.V. Stock (CAELUM Research Corp.) for their support. This research was supported by U.S. National Science Foundation grant OPP9526566 and 9904295 and NASA grants MTPE-00027 and NCG5374.

\section{REFERENGES}

Abdalati, W. and K. Steffen. 1997. The apparent effects of the Mt. Pinatubo eruption on the Greenland ice-sheet melt extent. Geophys. Res. Lett., 24(14), 1795-1797.

Comiso, J. C. 2000. Variability and trends in Antarctic surface temperatures from in situ and satellite infrared measurements. F. Climate, 13(10), 1674-1696.

Comiso, J. C., H. J. Zwally and J. L. Saba. 1982. Radiative transfer modeling of microwave emission and dependence on firn properties. Ann. Glaciol., 3, 54-58.

Fung, A. K. and M. F. Chen. 1981. Emission from an inhomogeneous layer with irregular interfaces. Radio Science, 16(3), 289-298.

Genthon, C. and A. Braun. 1995. ECMWF analyses and predictions of the surface climate of Greenland and Antarctica. f. Climate, 8(10), 2324-2332

Hollinger, J. P., J. E. Pierce and G. A. Poe. 1990. SSM/I instrument evaluation. IEEE Trans. Geosci. Remote Sensing, GE-28(5), 781-790.

Jacka,T. H. and W. F. Budd. 1991. Detection of temperature and sea ice extent changes in the Antarctic and Southern Ocean. In Weller, G., G. L. Wilson and B. A. B. Severin, eds. International Conference on the Role of the Polar Regions in Global Chan ge: proceedings of a conference held fune 11-15, 1990 at the University of Alaska Fairbanks.Vol. I. Fairbanks, AK, University of Alaska. Geophysical Institute/Center for Global Change and Arctic System Research, 63-70.

King, J. C. 1994. Recent climate variability in the vicinity of the Antarctic Peninsula. Int. F. Climatol., 14(4), 357-369.

National Snow and Ice Data Center (NSIDC). 1992. DMSP SSM/I brightness temperature and sea ice concentration grids for the polar regions on CD-ROM. Users'guide. Boulder, CO, National Snow and Ice Data Center. (Special Report 1.)

Shuman, C. A. and C. R. Stearns. 2001. Decadal-length composite inland West Antarctic temperature records. F. Climate, 14(9), 1977-1988.

Shuman, C. A., R. B. Alley, S. Anandakrishnan and C. R. Stearns. 1995. An empirical technique for estimating near-surface air temperature trends in central Greenland from SSM/I brightness temperatures. Remote Sensing Environ., 51 (2), 245-252.

Shuman, C. A., K. Steffen, J. E. Box and C. R. Stearns. 2001. A dozen years of temperature observations at the Summit: central Greenland automatic weather stations 1987-1999. 7. Appl. Meteorol., 40(4), 741-752.

Stearns, C. R. and G. A. Weidner. 1993. Sensible and latent heat flux estimates in Antarctica. In Bromwich, D. H. and C. R. Stearns, eds. Antartic meteorology and climatology: studies based on automatic weather stations. Washington, DC, American Geophysical Union, 109-138. (Antarctic Research Series 61.)

Stearns, C. R., L. M. Keller, G. A. Weidner and M. Sievers. 1993. Monthly mean climatic data for Antarctic automatic weather stations. In Bromwich, D. H. and C. R. Stearns, eds. Antarctic meteorology and climatology: studies based on automatic weather stations. Washington, DC, American Geophysical Union, 1-21. (Antarctic Research Series 61.)

Steffen, K. and11 others. 1993. Snow and ice applications of AVHRR in polar regions: report of a workshop held in Boulder, Colorado, 20 May 1992. Ann. Glaciol., 17, 1-16.

Stroeve, J. and K. Steffen. 1998. Variability of AVHRR-derived clear-sky surface temperature over the Greenland ice sheet. f. Appl. Meteorol., 37(1), 23-31.

Vaughan, D. G. and C. S. M. Doake. 1996. Recent atmospheric warming and retreat of ice shelves on the Antarctic Peninsula. Nature, 379(6563), 328-331.

Zwally, H. J. and S. Fiegles. 1994. Extent and duration of Antarctic surface melt. F. Glaciol., 40(136), 463-476. 